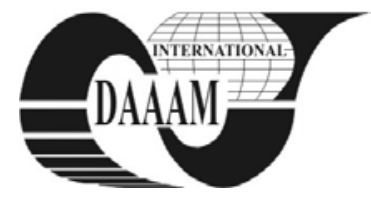

\title{
USE CASE POINTS METHOD IN SYSTEM ENGINEERING PROJECT ESTIMATION
}

\author{
SILHAVY, R[adek]; SILHAVY, P[etr] \& PROKOPOVA, Z[denka]
}

\begin{abstract}
The cost estimaton is an esencial need of the systemengineering project. The cost estimation is needed in the early project phase. In this article the project estimation based on the use case point method is presented. The key points in the presented methods are the system use cases
\end{abstract}

Key words: use case points, system engineering, project cost estimation

\section{INTRODUCTION}

The system engineereng is mandatory approach, which all development process uses. The system engineering as a discipline covers a broad number of subject at present time. It can focused on military systems (Balla, 2011), robotics (Quarda, 2011; Ciulanescu et al., 2009).

Mistakes in requirements elicitation therefore take very important role in a project success. In these article requirements elicitation methods are described in context of the system development and finally the clustered requirements are used for project estimation and the generic requirements engineering process is described.

In this paper, the estimation method for a systemengineering project is presented. The method is based on the clustered requirements approach (Silhavy et al., 2011) and by use case points method (Ribu, 2001).

The use case points method (Ribu, 2001) is an approach, based on the Use Case Model, which well know in the System Modeling Language. The model is used for the system function description. The Use Case model is composed of the actors, which are external entity and of the use cases. The use cases represent system functions or algorithms. Each of the use case has to realize one of the requirements as minimum.

The Use Case is description of the activity of the action in the system. The use case model in the system engineering consists of the actors, use case and associations.

A use case is written in form of the scenario. The scenario represents sequence of the steps, which represents using of the system by an actor.

The actors and scenarios are the base factor in the estimation methodology, called use case points.

Scenarios provide a brief description of an activity of an actor in a system. Other common definition describes a scenario as internal part of a business process, which is solved by a system itself (Silhavy, 2011).

For purpose of estimation, number (Sehlhors, 2007; Ribu, 2001) of steps in the scenario is significant. The number of steps represents the scenario or use case complexity; therefore, a system complexity is represents by the number of use cases.

For analyzing the system, complexity is necessary to analyze the use cases, which were created based on clustered requirements. The quality of use cases is important for the correct estimation without occurring error.

\section{THE ESTIMATION METHOD OVERVIEW}

For the porpuse of the estimation, the analysis of the use case is necessary. For the analysis are significant following parametrs:

1) The number of steps to complete the use case.

2) The number and complexity of the actors.

3) The technical requirements of the use case such as concurrency, security and performance.

4) The development team experience.

The generic use case point methods is described as following steps:

1) Technical Complexity Factor.

2) Environment Complexity Factor.

3) Unadjusted Use Case Points.

The Use Cases are clustered into three sets - Simple, Average and Complex.

The simple set contains use cases, which have software based interface and main path scenario has 4 steps as a maximum and implementation contains of 2 subsystems. Calculation value is 5 .

The average set contains use cases, which have user interface, data processing and main path scenario has 8 steps as a maximum and implementation is group of 5 subsystems. Calculation value is 10 .

The complex set contains use cases, which involves a technology control, mechanical user interface or very complex data processing. Main path has Over 8 steps; its implementation involves more than 5 subsystems. Calculation value is 15 .

Thirteen standard technical is shown in the table 1 . The factors exist to estimate (Silhavy, 2011) the impact on productivity that various technical issues have on an application. Each factor is weighted according to its relative impact. A weight of zero indicates the factor is irrelevant and the value 5 means that the factor has the most impact.

\section{ESTIMATION CASE STUDY}

The case study deals with the following project. In the Figure 1, there is proposed use case model of the basic drivers operations. In the Table 1 , contaions list of the actors and the use cases. The actors and the use cases are weighted and counted.

\begin{tabular}{|l|l|r|r||}
\hline Actors: & Complexity & Weight & Number \\
\hline Driver & Complex & 10 & 1 \\
\hline & & & \\
\hline Use cases: & & & \\
\hline Drive the vehicle & Complex & 15 & 1 \\
\hline Park & Avarage & 10 & 1 \\
\hline Start the vechicle & Simple & 5 & 1 \\
\hline Accelarete & Avarage & 10 & 1 \\
\hline Steer & Avarage & 10 & 1 \\
\hline Brake & Avarage & 10 & 1 \\
\hline \hline
\end{tabular}

Tab. 1. Use Case list 


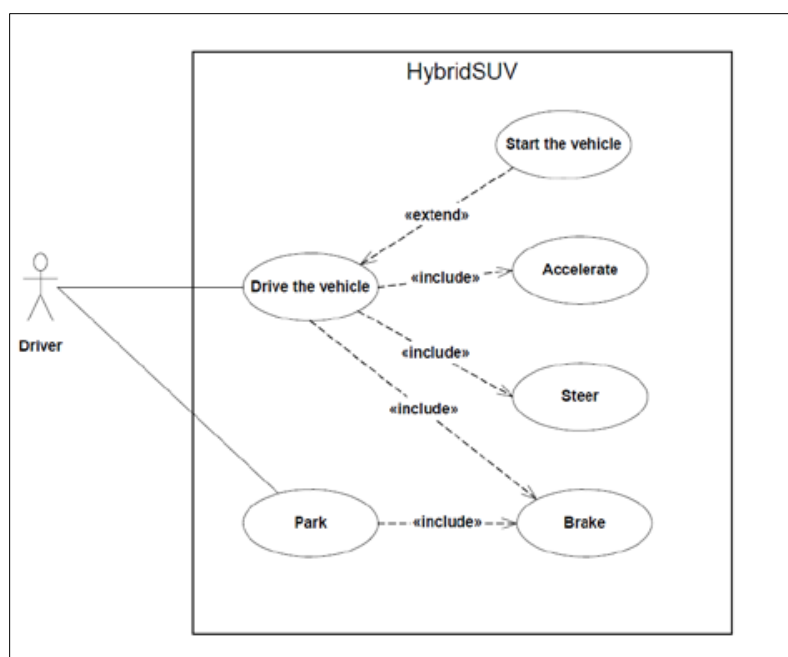

Fig. 1. Use Case model sample

Significance of the technical and environmental factors should set as $0 * 10$, where 0 has to effect and 10 represents the most significant factor.

Summary of the technical and environmental factor can be found in the Tables 3 and 4 .

\begin{tabular}{|l|l|r|}
\hline Technical Factor & Description & Weight \\
\hline$T 1$ & Distributed system & 2 \\
\hline$T 2$ & Performance & 1 \\
\hline$T 3$ & End User Efficiency & 1 \\
\hline$T 4$ & Complex internal Processing & 1 \\
\hline$T 5$ & Reusability & 0,5 \\
\hline$T 6$ & Easy to install & 0,5 \\
\hline$T 7$ & Easy to use & 1 \\
\hline$T 8$ & Portable & 1 \\
\hline$T 9$ & Easy to change & 1 \\
\hline$T 10$ & Concurrent & 1 \\
\hline$T 11$ & Special security features & 2 \\
\hline$T 12$ & $\begin{array}{l}\text { Provides direct access for } \\
\text { third parties }\end{array}$ & 2 \\
\hline$T 13$ & $\begin{array}{l}\text { Special user training facilities } \\
\text { are required }\end{array}$ & 1 \\
\hline$T 14$ & Sociotechnical system & 1 \\
\hline$T 15$ & Business Critical & 1 \\
\hline$T 56$ & factors list & 1 \\
\hline
\end{tabular}

Tab. 2. Technical factors list

Environmental Complexity estimates the impact on productivity that various environmental factors have on a system.

Each environmental factor (see table 2) is evaluated and weighted according to its perceived impact and assigned a value between 0 and 5 . A value of 0 means the environmental factor is irrelevant for this project; 3 is average; 5 means it has strong influence.

Technical Factors are calculated as TTF: $0.6+(0.01 *$ Global Technical Factor. The global technical factor is calculated as sum of Weight * Effect for each T.

For sample project TTF is 1.45 .

Environmental Factors are calculated as ETF: $1.4+(-0.03 *$ Global Enviromental Factor.
The global environmental factor is calculated as sum of Weight * Effect for each E.

For sample project ETF is 1.1.

\begin{tabular}{|l|l|r||}
\hline $\begin{array}{l}\text { Environmental } \\
\text { Factor }\end{array}$ & Description & Weight \\
\hline E1 & $\begin{array}{l}\text { Familiarity with System } \\
\text { Designing }\end{array}$ & 2 \\
\hline E2 & Systém Domain Experience & 1 \\
\hline E3 & SysML Experience & 2 \\
\hline E4 & Lead analyst capability & 1 \\
\hline E5 & Motivation & 2 \\
\hline E6 & Stable Requirements & -2 \\
\hline E7 & Sub- Contractors & 2 \\
\hline E8 & Difficult Integration & -2 \\
\hline E9 & Ecological Evaluation & -2 \\
\hline E10 & Public Importancy & \\
\hline \hline
\end{tabular}

Tab. 3. Enviromental factors list

Final result of calculation, the number of use case points is calculated as follows:

(Unadjusted Use Case + Unadjusted Actors) * TTF * ETF. In our example, total number of use case points is 111.65 .

Final estimation is based on number of working our per 1 use case point. It is usually set approx. 30 hours per 1 point.

\section{CONCLUSION}

The idea of the contribution was to introduce the estimation mehod for the system engineering projects.

The method is inspirated by methods used in the field of software engineering. For the porpuse of the system engineering the estiomation factors were recaluted and resetup.

Further research in system modeling is focused on the improvement of the appropriate calculation values, which probably the most important in the estimation factors.

Further research will be focused in improving accuracy of technical and environmental factors.

\section{ACKNOWLEDGEMENTS}

This work was supported by the Ministry of Education, Youth and Sports of the Czech Republic under the Research Plan No. MSM 7088352102.

\section{REFERENCES}

Balla, J. 2011, Dynamics of mounted automatic cannon on track vehicle. International Journal of Mathematical Models and Methods in Applied Sciences, Vol. 5, No. 1, page numbers (423-432), ISSN 1998-0140

Ciulanescu, M. V. \& Diaconu, A. (2009). Mobile Robot Control using the Bluetooth Technology, Annals of DAAAM for 2009 \& Proceedings of the 20th International DAAAM Symposium, 25-28th November 2009, Vienna, Austria, ISSN 1726-9679, ISBN 978-3-901509-70-4, Katalinic, B. (Ed.), pp. 1115-1116, Published by DAAAM International Vienna, Vienna

Ribu, K. (2001) Estimating Object-Oreinted Software Projects with Use Case. Unvirstiy in Oslo, Oslo

Silhavy R., Silhavy P. \& Prokopova, Z. (2011). Clustered Requirements in System Engineering Project Estimation. Internatinal Journal of Mathematical models and Methods in Applied Sciences, Vol. 5, No. 1, (June 2011) page numbers (1052-1059), ISSN 1998-0140

Quarda, H. 2011. Cognitive tasks behavior of intelligent autonomous mobile robots, International Journal of Mathematical Models and Methods in Applied Sciences, Vol. 5, No. 3, page numbers (610-619), ISSN 1998-0140 